\title{
Isolated intestinal ganglioneuromatosis - A rare entity
}

\author{
Laudari U', Rupakheti S², Bohara TP3 , Joshi MR', Lakhey $\mathbf{M}^{5}$
}

'Uttam Laudari, Resident; ${ }^{2}$ Shail Rupakheti, Lecturer; ${ }^{3}$ Tanka Prasad Bohara, Assistant Professor; ${ }^{4}$ Mukunda Raj Joshi, Associate Professor; Department of General Surgery; ${ }^{5}$ Mamta Lakhey, Professor; Department of Pathology, Kathmandu Medical College, Kathmandu, Nepal.

\begin{abstract}
Intestinal ganglioneuromatosis are rare benign tumour of ganglionic cell origin, most of them associated with neurofibromatosis type I and multiple endocrine neoplasia type IIB. They are benign tumours with rare malignant transformation, have a varied clinical presentation and long indolent course. Surgical resection is the only modality of treatment and diagnosis is based on histopathological examination and immunohistochemistry.

We report a case, 55 year old male who was diagnosed as a case of isolated intestinal ganglioneuromatosis, i.e no association with neurofibromatosis type I and multiple endocrine neoplasia type IIB. He is on regular follow up with normal daily activities and no evidence of recurrence.
\end{abstract}

Key words: Ganglioneuromatosis, Small Intestine

\section{INTRODUCTION}

G anglioneuromas are well differentiated tumours, arising from ganglion cells, nerve fibres and supporting cells. They are rare tumours mostly occuring after 10 years of age, often located in posterior mediastinum and retroperitoneum; $41.5 \%$ arising from thoracic cavity, $37.5 \%$ in abdominal cavity excluding adrenal gland and $21 \%$ of them from adrenal parenchyma1. Other sites include skin, retro pharynx, paratesticular region and gastrointestinal tract. Ganglioneuromatous polyposis also has been found to be associated with neurofibromatosis type I (NF I), multiple endocrine neoplasia type IIB (MEN IIB), Cowden syndrome and even as isolated lesions ${ }^{2,3}$.

These have a long course, varied clinical presentation and none of the radiological investigations are conclusive. Association with NF I and MEN IIB have been reported but there are only few reported cases of isolated intestinal ganglioneuromatosis (IGNs).

Address for correspondence

Dr. Uttam Laudari

3rd year Resident

Department of General Surgery

Kathmandu Medical College Teaching Hospital

Sinamangal, Kathmandu.

E-mail:youttam@hotmail.com

\section{CASE REPORT}

A 55 year old male presented with complaints of pain in right lower abdomen for 10 years, weight loss of $10 \mathrm{~kg}$ in last 4 months, constipation, melena on and off for 2 years, and his symptoms were increasing in severity in last 4 months. He is a smoker, consumes Gutkha, and is an occasional alcohol consumer, has no similar illness in family. On examination, he was average built, BMI-22 kg/ $\mathrm{m}^{2}$ with normal respiratory, cardiovascular, abdominal and per rectal examination. Blood investigations were normal except raised C-reactive protein of $50 \mathrm{mg} / \mathrm{l}$ (normal limit up to 10). No any specific tumour markers were done. Colonoscopy showed ulcerated thickened mucosa with granulation tissue in terminal ileum, a polypoid $1-2 \mathrm{~cm}$ mass with eroded haemorrhagic superficial mucosa suggestive of terminal ileum ulcer with mass. Colonoscopic biopsy from ileal polyp was consistent with inflammatory fibroid polyp and was negative for tuberculosis and malignancy. Contrast enhanced computerized tomography of abdomen revealed diffuse circumferential wall thickening of a very long segment of distal ileum up to ileocecal junction, maximum thickness of $16.7 \mathrm{~mm}$ with some enhancement and no focal mass lesion within the bowel. Dilatation of small bowel was seen just proximal to involved ileum with multiple enlarged enhancing mesenteric lymph nodes, largest one measuring $31 \mathrm{~mm}$. Omental thickening with enhancing nodules were also seen. All of these features were consistent with small bowel lymphoma. Patient 
underwent right hemicolectomy with resection of $5 \mathrm{~cm}$ of non-involved ileum and colon on either side of lesion with affected mesentery and ileorectal anastomosis for chronic distressing abdominal pain. Intraoperatively distal ileum was thickened and firm, with multiple enlarged mesenteric lymph nodes and no evidence of metastasis. Extra $10 \mathrm{~cm}$ of distal ileum was also removed which was involved by disease.

\section{HISTOPATHOLOGY}

\section{GROSS FINDINGS}

Small intestine felt firm, cut surface showed mucosal elevations predominantly in small intestine $11.5 \mathrm{~cm}$ away from proximal resected margin and $10 \mathrm{~cm}$ away from distal resected margin. These areas also showed ulceration along with loss of mucosal folds at places. The attached mesentery showed numerous nodules size ranging from 0.5 to $2.5 \mathrm{~cm}$ in diameter. (Figure 1, Figure 2 and Figure 3)

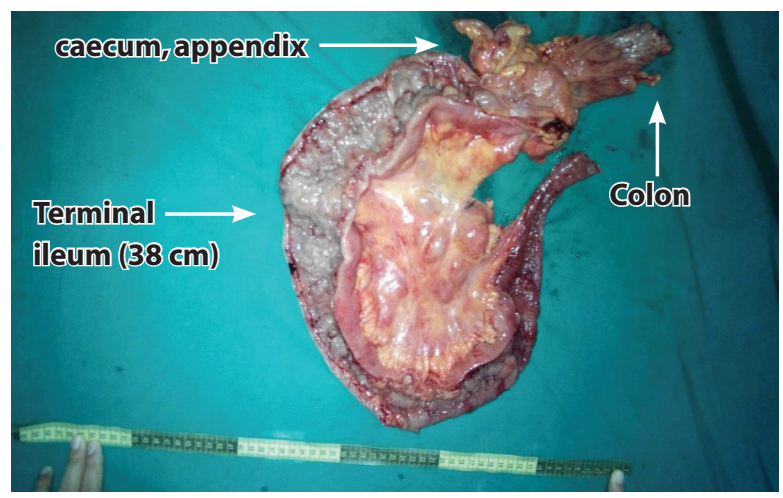

Figure 1: Gross specimen

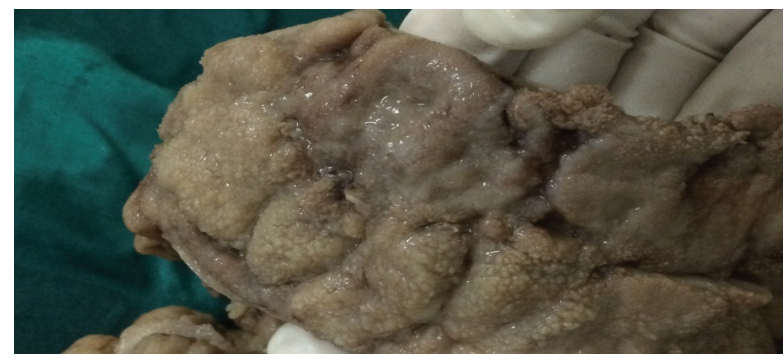

Figure 2: Cut section of gross specimen showing multiple mucosal elevations with ulceration

\section{MICROSCOPIC FINDINGS}

Sections from intestine revealed prominent proliferation of nerve fibres with ganglion cells in submucosa that extended throughout the muscular layer into subserosa. (Figure 4 and 5) Sections from mesenteric nodules showed well circumscribed masses with proliferation of

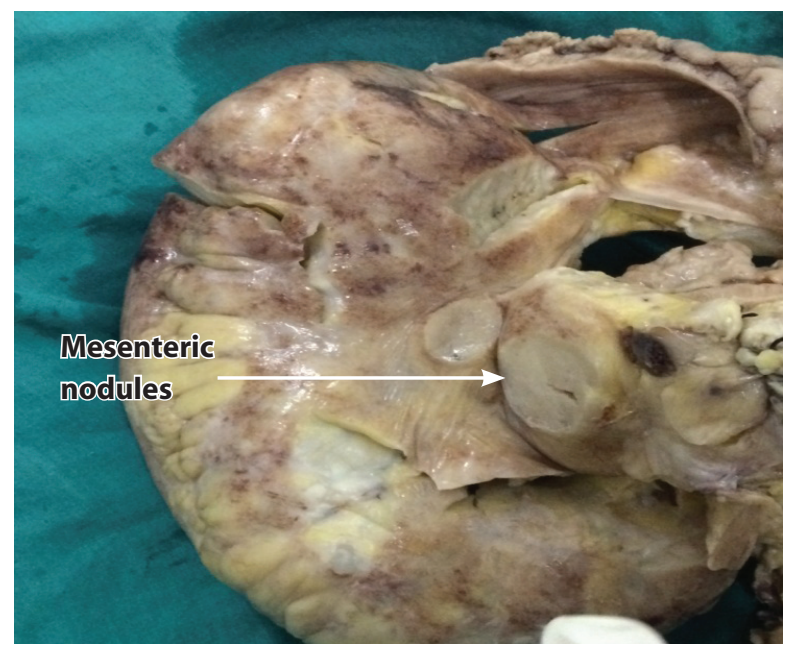

Figure 3: Showing mesenteric nodules

elongated cells with wavy nucleus along with collagen bundles. Immunohistochemistry was positive for S-100. (Figure 6)

The postoperative period was uneventful and the patient was discharged on $8^{\text {th }}$ post operative day.

Systemic syndromes namely MEN IIB and NF I were excluded by thorough physical examination. He had no any evidence of dermal neurofibromas, café-au-lait macules, Lisch nodules and marfanoid habitus. He also had no evidence of thyroid and adrenal tumours on imaging. On follow up, his physical examination, routine investigation and imaging were within normal limit.

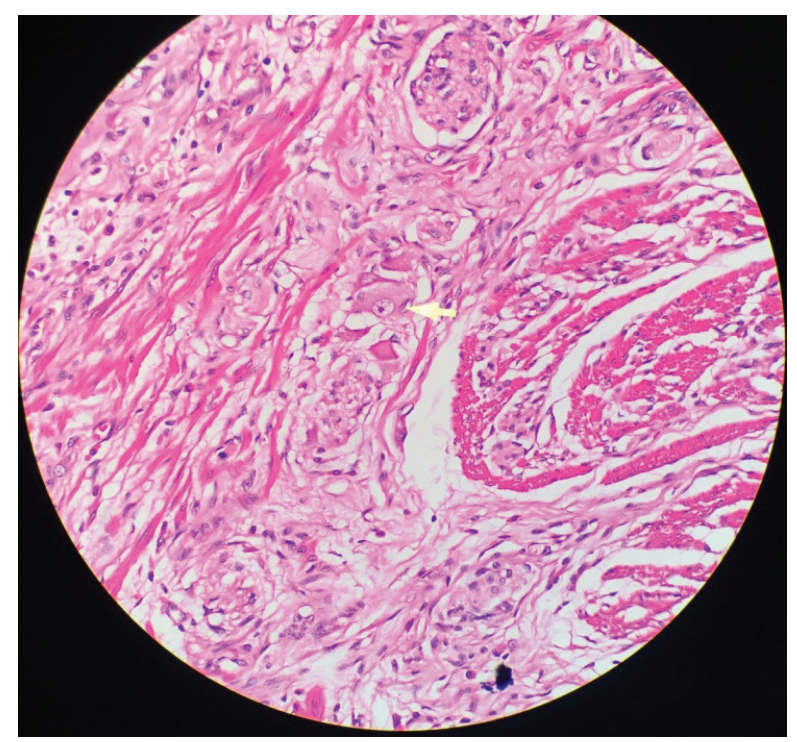

Figure 4: 40X H\&E Nerve fibres and ganglion cells 


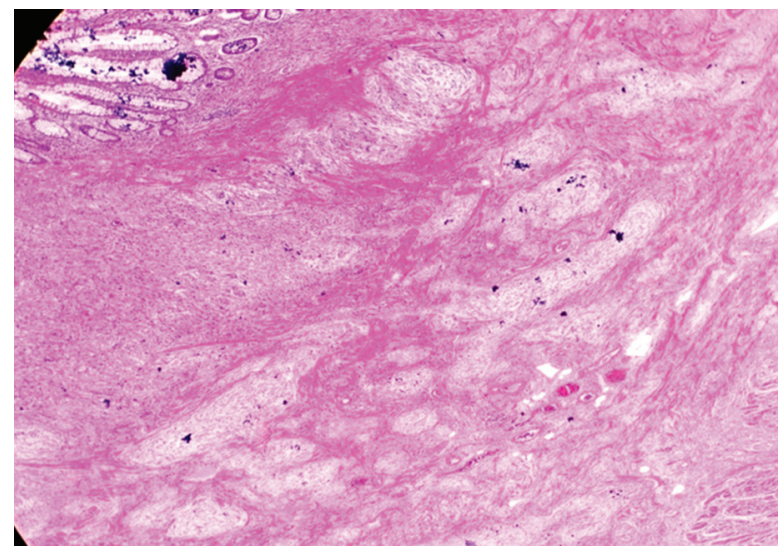

Figure 5: 40X H\&E Submucosal proliferation of nerve fibres

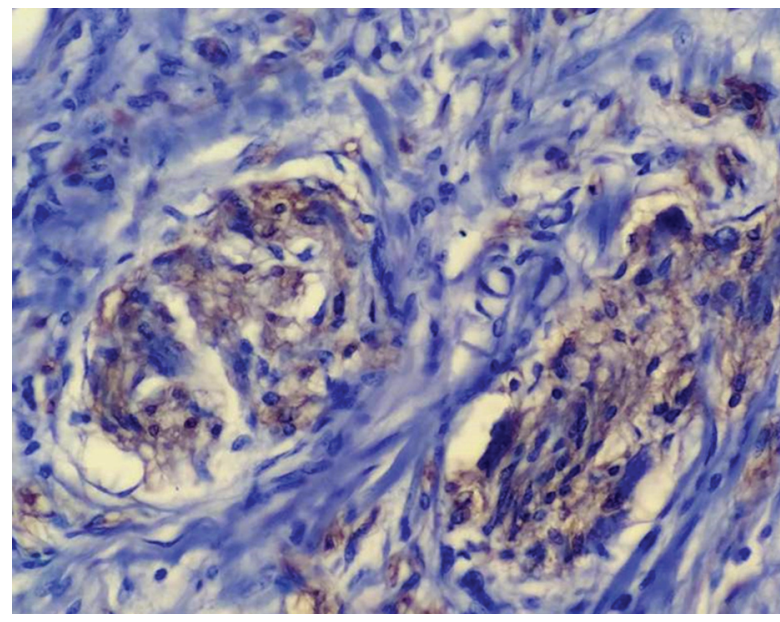

Figure 6:400X S-100 positive

\section{DISCUSSION}

We presented a case of isolated intestinal ganglioneuromatosis in a 55 year old gentle man who presented with complaints of vague abdominal discomfort, constipation and intermittent melena. Colonoscopy and biopsy were inconclusive. Capsule endoscopy and double balloon endoscopy could not be done. Patient underwent right hemicolectomy and ileorectal anastomosis for distressing chronic abdominal pain. Ileum was involved; no association with MEN IIB and NF I. Diagnosis was made on the basis of histopathologic findings, confirmed by immunohistochemistry (S-100 positive).

Ganglioneuromas (GNs) of the gastrointestinal (GI) tract are rare benign and well differentiated tumours characterized by hyperplasia of ganglion cells, nerve fibres and supporting cells $s^{4,5}$. The tumour shows transmural proliferation of nerve plexus in bowel and has strong association with NF 1 and MEN IIB ${ }^{5}$. It had also been seen associated with familial adenomatous polyposis coli, Cowden disease, tuberous sclerosis and colon adenocarcinoma ${ }^{6}$.

Shekitka et al. in 1994 studied 28 cases of intestinal GNs in relation to NF I and divided it into three groups i.e. polypoid $\mathrm{GN}$, ganglioneuromatous polyposis and diffuse ganglioneuromatosis. Appendix, colon, terminal ileum right colon, sigmoid colon, rectal and stomach involvement of diffuse GNs was found ${ }^{6}$. Based on their literature review they found diffuse ganglioneuromatosis associated with MEN IIB and NF I are strong factor for extensive neurogenic diseases.

Maria Teresa Herranz Bachiller et al. in 2013 reported a case of 40 year old female with diffuse intestinal ganglioneuromatosis with Cowden syndrome which was also a rare presentation. She presented with rectal bleeding, had prior history of breast and endometrial tumour; on thorough clinical and laboratory investigations were found consistent with Cowden syndrome ${ }^{2}$.

Khin Thway et al. in 2009 in their literature review found a total 18 cases of diffuse ganglioneuromatosis in association with NF I .The median age group was 32 years with male predominance. The most common site was colon. Small bowel involvement associated with NF I and malignant nerve sheath tumour was again a rare presentation in their series ${ }^{7}$.

Atitar et al. reported a case of isolated ileal ganglioneuromatosis, where the presentation was a 58 year old man with obscure Gl bleeding, and was operated for persistent IDA, later on histopathology revealed ileal ganglioneuromatosis, with no association with NF I and MEN IIB . They recommended role of video capsule endoscopy for diagnosis.

Alexandra Fernandes et al. in 2015 reported a case of another isolated ileal ganglioneuromatosis, who presented with iron deficiency anaemia, with no visible bleeding and requiring frequent blood transfusion. Video capsule endoscopy showed an ulcerated stenosis in small bowel but biopsies taken at balloon enteroscopy was not conclusive. Laparotomy and resection of stenotic segment was done which revealed diffuse intestinal ganglioneuromatosis and no association with NF I and MEN IIB ${ }^{8}$.

DY Cheung et al. conducted a study of role of video capsule endoscopy in small bowel tumour with diagnostic impact of $52.6 \%$. Out of 57 small bowel tumours, 30 radiologically negative tumours (lymphoma, 
subepithelilal, epithelial, polyps and vascular masses) were detected by capsule endoscopy ${ }^{2}$. However the role of capsule endoscopy was inconclusive in intestinal GNs in previous study ${ }^{8}$.

Ganglioneuroma of small bowel presenting with acute abdomen has been reported from Nepal, but diffuse GNs without syndromic manifestation are the rare presentation $^{3,9}$.

GNs can be suspected radiologically but diagnosis may be missed due to its rare presentation. The diagnosis of GNs are based on histopathologic examination and confirmed by immunohistochemistry. Histopathologic features are uniform appearance, occurring in small clusters or nests. They appear as bundles of longitudinal and transversely originated Schwann cells which arrange haphazardly. Schwann cells have mature ganglions with voluminous cytoplasm and one to three nuclei within it. Diffuse proliferation of nerve fibres, ganglion cells, and supporting cells of the enteric nervous system, with high acetylcholinestarase activity may be seen. They may have fusiform growth pattern with hyperplastic expansion of myenteric plexus and even transmural ganglioneuromatomas proliferation distorting the myenteric plexus, infiltrating the adjacent bowel wall ${ }^{1,7,10}$.
Though these are benign tumours, rarely metastatic focus of ganglioneuroma may be encountered in a lymph node adjacent to tumour mass or at distant site, which are assumed to be neuroblastoma. These malignant components resemble with malignant peripheral nerve sheath tumour'. Since it has association with MEN IIB, prompt evaluation by endocrinologist and oncologist is must prior discharge and during follow up ${ }^{10}$.

\section{CONCLUSION}

Diffuse intestinal ganglioneuromatosis is a rare benign tumour, with proven association with NF I and MEN IIB and few cases of isolated IGNs have been reported. Patient usually has a long history, with varied clinical presentation of constipation, diarrhoea, obscure $\mathrm{Gl}$ bleeding, unexplained weight loss etc. Radiological investigation may be inconclusive due to its rarity. The role of Video capsule endoscopy is yet to be established. Surgical resection of the involved bowel is the treatment of choice. Diagnosis is based on the gross and histopathologic findings. Immunohistochemistry may be confirmatory. Since it is associated with NF I and MEN IIB, thorough examination and investigations to rule out these syndromes are mandatory before discharge and follow up.

\section{REFERENCES}

1. Sharon W, Weiss JRG. Soft Tissue Tumors. Elsevier Inc.2008; Fifth. 960-3.

2. Herranz Bachiller Mt Fau - Barrio Andres J, Barrio Andres J Fau - Pons F, Pons F Fau - Alcaide Suarez N, Alcaide Suarez N Fau - Ruiz-Zorrilla R, Ruiz-Zorrilla R Fau - Sancho Del Val L, Sancho Del Val L Fau - Lorenzo Pelayo S, et al. Diffuse intestinal ganglioneuromatosis an uncommon manifestation of Cowden syndrome. World J Gastrointest Oncol. 2013;5(2):34-7.

3. Atitar I, Serraj I, Amrani L, Raissouni F, Kettani F, Raiss $\mathrm{M}$, et al. Isolated ileal ganglioneuromatosis in adult revealed by obscure digestive bleeding. Clin Res Hepatol Gastroenterol [Internet]. 2011;35(11):7712. Available from: http://dx.doi.org/10.1016/j. clinre.2011.07.012

4. Mate I, losif C, Dinu D, Constantinoiu S. Solitary ganglioneuromatosis of the descending colon, presenting as giant retroperitoneal tumour. Chirurgia (Bucur) [Internet]. 2013;108(4):584-8. Available from: http://www.ncbi.nlm.nih.gov/pubmed/23958108

5. Lu C, Qiu Y, Lu X, Li G, Bu H. Synchronous diffuse ganglioneuromatosis and multiple schwannomas of the colon: A case report and literature review. Exp Ther Med. 2015;9(3):733-6.

6. Kris M, Shekitka LHS. Ganglioneuromas of the Gastrointestinal Tract Relation to Von Recklinghausen Disease and other Multiple Tumor Syndromes. Am J Surg Pathol. 1994;18(3):250-7.

7. Thway K, Fisher C. Diffuse ganglioneuromatosis in small intestine associated with neurofibromatosis type 1. Ann Diagn Pathol [Internet]. 2009;13(1):504. Available from: http://dx.doi.org/10.1016/j. anndiagpath.2007.06.001

8. Fernandes A, Ferreira AM, Serra P, Carvalho L. Intestinal ganglioneuromatosis: an unusual aetiology for occult gastrointestinal bleeding. BMJ Case Rep [Internet]. 2015. Available from: http://casereports. bmj.com/lookup/doi/10.1136/bcr-2015-211764

9. Pratap A, Tiwari A, Pandey S, Yadav RP, Agrawal A, Sah BP, et al. Ganglioneuroma of small bowel mesentery presenting as acute abdomen. J Pediatr Surg. 2007;42(3):573-5.

10. Feichter S, Meier-Ruge WA, Bruder E. The histopathology of gastrointestinal motility disorders in children. Semin Pediatr Surg [Internet]. 2009;18(4):206-11. Available from: http://dx.doi. org/10.1053/j.sempedsurg.2009.07.002 